\title{
DE PETRÉS A BIGASTRE: UNA EXCURSIÓ PER LA LLENGUA DE LES CARTES DE POBLAMENT VALENCIANES DEL XVII
}

\author{
FROM PETRÉS TO BIGASTRE: AN EXCURSION \\ THROUGH THE LANGUAGE OF VALENCIAN \\ SETTLEMENT LETTERS FROM 17TH CENTURY
}

\author{
Francesc Feliu \& Joan Ferrer \\ Universitat de Girona \\ francesc.feliu@udg.edu / joan.ferrer@udg.edu
}

Resum: Les cartes de poblament d'època moderna, molt abundants al País Valencià sobretot com a conseqüència de les repoblacions que seguiren a l'expulsió dels moriscos (I609), no han estat gens estudiades fins ara des del punt de vista lingüístic, en bona mesura perquè fins fa pocs anys no disposàvem d'un repertori significatiu d'aquesta mena de documents. Es tracta de textos de registre jurídic que incidien molt directament en la vida d'una part important de la població — també, indirectament, en la idea que la gent pogués tenir de la llengua autòctona. Aquest treball intenta fer una primera aproximació a l'estudi de les cartes de poblament valencianes del segle XviI, valorant el grau de persistència de l'ús del valencià en aquest textos, i també dels models lingüístics tradicionals.

Paraules clau: cartes de poblament, valencià, segle XVII, models lingüístics, usos lingüístics.

Abstract: The town charters of modern period, very abundant in the Valencian Country, mainly as a result of the repopulations that followed the expulsion of the Moriscos (I609), have not been studied so far from a linguistic point of view to a large extent because until a few years ago we did not have a significant repertoire of this type of documents. These are texts of legal linguistic variety that directly affected the life of an important part of the population —also, indirectly, the idea that people could have of their native language. This paper attempts to make a first approach to the study of Valencian town charters from the i7th century, evaluating the degree of persistence of the use of Valencian in these texts, as well as the persistence of traditional linguistic models.

Key words: Town Charters, Valencian, Xvir Century, lingüístic models, lingüístic uses. 
Francesc Feliu \& Joan Ferrer

De Petrés a Bigastre: una excursió per la llengua de les cartes de poblament valencianes del XVII

Les cartes de poblament constitueixen un gènere bastant específic dins l'àmbit de la documentació jurídica, que a les terres de València va tenir una profusió molt important, ja que atenyen des de l'època de la conquesta fins ben entrat el segle XviII, a causa dels successius episodis de repoblament posteriors a l'expulsió dels moriscos. Historiadors $\mathrm{i}$ arxivers han anat exhumant i publicant, en les darreres dècades, una gran quantitat d'aquests textos que, en la majoria dels casos, tenen un interès purament testimonial i concerneixen gairebé exclusivament els actuals habitants de les comarques o poblacions de referència. Tanmateix, des de la història cultural i lingüística, que ha desatès en general aquest tipus de documents, poden plantejar-se també sobre aquest tema algunes qüestions d'un cert interès. Avui, que disposem d'una visió de conjunt de tots aquests materials com la que ens proporcionen els tres voluminosos volums de Cartes de poblament valencianes modernes (segles XVI-XVIII), publicades per la Universitat de València entre 20I5 i 20I7, amb més de tres-cents documents aplegats, podem començar en efecte a apuntar algunes consideracions a propòsit dels usos lingüístics al territori valencià en un àmbit tan concret, però tan abundant i tan estretament vinculat a la vida local $\mathrm{i}$ als interessos particulars de tanta gent.

Les qüestions d'interès per a la història de la llengua, en realitat, són dues: la primera, quina fou la persistència de l'ús de la llengua catalana en la redacció d'aquesta mena de documents; la segona, quin tipus de llengua s'utilitza en els documents que són redactats en valencià. D'ambdues coses n'hauríem de poder extreure informacions que s'afegissin a les nombroses dades de què disposem ja avui sobre el català de l'època moderna, i que contribuïssin a millorar la comprensió d'aquest període encara tan mal conegut de la nostra història cultural. Per raons d'espai i de temps, aquest nostre treball temptatori vol circumscriure's exclusivament al segle xviI, que correspon al gruix dels nous poblaments derivats de l'expulsió dels moriscos, un fet històric d'innegables repercussions també en el terreny lingüístic.

\section{PRESÈNCIA DEL VALENCIÀEN LES CARTES DE POBLAMENT DELXVII}

La tipologia documental de les cartes de poblament presenta, segons que ens adverteixen els especialistes, poques variacions respecte dels models de segles anteriors. Enric Guinot, en el pròleg al primer volum del recull ja esmentat de cartes de poblament valencianes modernes (Guinot \& Ardit 20I5: 8) explica que:

Tot i els grans canvis polítics [...] la societat valenciana dels segles XVI al XVIII continuà immersa en el mateix tipus de societat feudal-senyorial que només desapareixeria amb la 
revolució burgesa. Per això, en el món rural, era lògic que, tant senyors laics i eclesiàstics com la mateixa corona, continuassen emprant el mateix tipus de documents jurídics que havien mostrat la seua utilitat en els segles anteriors pel que fa a la forma d'establir les condicions de vida en una comunitat.

Si el format i l'estructura de les cartes de poblament van mantenir-se amb poques alteracions al llarg dels segles, ¿va fer-ho també el suport lingüístic amb què es redactaven?

Sabem, encara que no és tampoc un terreny gaire fressat, que les cartes de poblament medievals, com tants altres documents de caràcter notarial, usaren de forma preeminent el català a partir del segle XIV, independentment que incloguessin protocols inicials i/o finals redactats en llatí. Els termes del document implicaven gent comuna, i havien de ser clars i entenedors. ${ }^{1}$ A més, com és conegut, la institució notarial a tota la Corona d'Aragó tingué un desenvolupament extraordinari, i usà la llengua pròpia amb persistència, en molts casos, fins a la prohibició expressa d'aquest ús, ben entrat el segle XIx. ${ }^{2}$

Caldria tenir en compte, però, si el bilingüisme territorial històric de l'antic Regne de València pogué afavorir l'ús del castellà en aquesta mena de documents en aquells territoris que ja eren castellanoparlants. Es tracta d'una hipòtesi difícil de comprovar, com sigui que els intervinents en la fixació de les condicions del poblament no són només, ni principalment, els pobladors ja existents al territori, sinó els nobles que tenen el domini dels llocs i els futurs pobladors. Sogorb, Pedralba o Bugarra per exemple, que són castellanoparlants, tenen la carta de poblament en valencià. És cert, però, que les directrius politicolingüístiques d'alguns estaments que intervenien sovint directament en la producció de les cartes pobles, com ara el bisbat de València, tendiren a introduir ja des de ben aviat la lingua generalis hispanica en la redacció dels documents oficials, d'allà on fossin. Sigui com sigui, la tendència a redactar en castellà les cartes de poblament, i no sols en els llocs en què l'entorn lingüístic era castellà, va anar augmentant a mesura que s'avançava en l'edat moderna, i l'ús del castellà esdevindrà exclusiu a partir del segle XviII. Els esdeveniments polítics derivats de la Guerra de Successió espanyola marcaran un punt d'inflexió clar en relació a l'ús lingüístic en aquest tipus de documents.

Ara bé, si prenem com a referència el panorama que ens n'ofereix el tercer volum del recull monumental de Guinot i Ardit (20I7), que arrenca el I6I2 i arriba fins

I. Podem trobar una presentació succinta d'aquest tipus de documents, per exemple, a Amillo (20Io).

2. Vegeu sobre això, per exemple, un treball recent d'Olga Fullana (2017).

Caplletra 66 (Primavera, 2019), p. 121-135 
a les darreries del segle XVIII, ${ }^{3}$ podem observar com al llarg del sis-cents la proporció entre els textos redactats en valencià i els que usen el castellà és encara favorable als primers, en una relació aproximada de dos terços a un (62 cartes en valencià, 37 en castellà). Algunes d'aquestes cartes, en la mesura que modifiquen o complementen cartes anteriors, citen en el seu interior altres documents escrits, de vegades, en l'altra llengua, amb la qual cosa - $\mathrm{i}$ tenint en compte que solen incloure també formulismes en llatí- constitueixen de fet documents multilingües.

El català com a llengua institucionalitzada, com a llengua que empara els registres de la formalitat i els usos públics, es manté, doncs, amb prou vigor tot al llarg del disset, en un context en què, de fet, és bastant irrellevant que coincideixi o no amb la llengua que parlava realment la població. Tal com ho corrobora el notari de la carta de població d'Alboi, terme actual del Genovés, encara al darrer terç del segle XVIII (I766) la llengua de l'escriptura quedava al marge de la immensa majoria dels «pobladors» concernits, si no de tots (Guinot \& Ardit 2017: 2539):

Y de los otorgantes, a los quales doy fé conozco, lo firmó dicho señor don Juan Escribá y no los demás porque dixeron no saber, ni los testigos por lo mismo, que lo fueron José Cavanes, texedor, y Vicente Sánchiz, labrador, vecinos del lugar del Genovés. De todo lo qual doy fé y de que en esta villa no se encontró, por su muy corto vecindario, persona alguna que sepa escribir.

\section{LA LLENGUA DE LES CARTES VALENCIANES DEL XVII}

Ateses les característiques i les dimensions d'aquest treball, hem desestimat de fer una anàlisi exhaustiva de la llengua de totes les cartes de poblament siscentistes redactades en valencià que ara tenim a l'abast. Ja que hem utilitzat el darrer volum del monumental recull de Guinot i Ardit per a assajar una visió perspectiva de l'evolució de les coses al llarg del xvir, ens proposem ara un breu exercici de buidatge gramatical de dues cartes de poblament d'aquest volum: la primera que hi apareix escrita en valencià, el I6r2, i la darrera, que és de i7or.

La carta de poblament de Petrés, al camp de Morvedre, va ser atorgada el I3 de maig de I6I2 després que el lloc hagués quedat despoblat el I609 quan pràcticament tots els seus habitants foren embarcats cap a Orà. La carta de poblament de Bigastre, a tocar d'Oriola, en canvi, va ser atorgada el i6 d'octubre de I70I, i dona origen a

3. Resulta més "panoràmic» aquest tercer volum que no pas el segon, que se circumscriu estrictament a l'abundantíssima documentació dels anys I6II i I6I2, el moment àlgid dels nous poblaments, just després de l'expulsió dels moriscos. 
una nova vila, fundada dins el terme de la Torre de Masquefa. El viatge entre les dues cartes, que és també un viatge geogràfic de nord a sud que travessa bona part del País Valencià, i un viatge cronològic des dels inicis del Xvir fins a les darreries de l'antic Regne de València, ens permetrà d'esbossar la trajectòria de la llengua catalana en aquest terreny encara tan desconegut.

\section{I LA CARTA DE POBLAMENT DE PETRÉS (I6I 2)}

En el terreny de les grafies hi trobem, d'entrada, un grau de vacil.lació notable: lloctinent (preàmbul) ${ }^{4}$ / loch (preàmbul); avasallar (I) / avassallar-se (5); vasalls (I) / vassall (I3); exersisi (I) / excersir (I) / excercit (I); capitulasió y poblasió (5); sa casa (5) / la cassa (5) / casses (I); aixi (I) / baxa (I) / sexanta (2); senç (I) / cens (3); lloyme (2) / lloysme (3) / llö̈sme (5); sacraments (I) / sagraments (4); homenatges (I) / homenages (4); quatre messos (5); arrobes (I5) / arroves (I5); aprobava (consideracions finals) / aprovava (últim paràgraf); almàcera (I6) / almàsera (I6); acessor de la cort (2I).

La tendència del text és a no marcar les elisions pròpies de l'oralitat, tot i que hi ha alguns exemples escadussers d'elisions: que.ls (2), que.s (2I), se'ls stabliran (6), si.s secaran (I3), s'o retura (I8), d'aquells (I9) — però de aquells (22), la elecció (4), se avasallaran (5), etc.

En l'àmbit de la morfologia, podem destacar l'aparició de formes reforçades d'alguns pronoms febles —es sembraran (9) — al costat de les més sistemàtiques formes plenes d'articles i pronoms - lo secà (2). Els possessius àtons s'usen sistemàticament — sos antesessors (I), sa casa (5) — i apreciem alguns usos de caràcter col-loquial en els numerals — hu dels tres (4) — i en els indefinits_y altres qualsevols (9). Pel que fa a la morfologia verbal, trobem participis analògics com establida (2) o obtesa (5), i alternança en el radical en el cas de tenguts (I6) / tinguts (5). També hi ha algunes formes espúries del subjuntiu —puixen (5), véna (vengui) (6)—o del gerundi —comparent.

Quant a la sintaxi, ressenyem tot seguit alguns dels fenòmens més interessants:

i. Article amb valor neutre: $y$ tot lo demés (I8).

ii. $\quad$ Futur amb valor de present: los dits vasalls y nous pobladors que seran [: són] al present y per temps seran en lo esdevenidor (19).

4. Indiquem entre parèntesis el paràgraf on es troba el mot o fragment de text citat. En la carta de Petrés els editors indiquen els paràgrafs amb xifres romanes i en la de Bigastre amb xifres aràbigues. Nosaltres usem en tots dos casos les aràbigues.

Caplletra 66 (Primavera, 2019), p. 121-135 
iii. Gerundi que expressa acció simultània: secrestador del lloch de Petrés y tenint comissió del doctor S. (preàmbul); pagant lo dret de la almàsera conforme se paga en los llochs sircumvehins (I6).

iv. Manca de concordança: los sacraments y homenatges de fidelitat acostumat (I); la qual dita sisena part les haja de rebre lo senyor (I2).

v. Elisió de la preposició en una seqüència coordinada: en lloch [de] y per lo senyor (preàmbul).

vi. Ús del verb obligar sense preposició: se obligue [a] avassallar-se en dit loch (5).

vii. Elisions: la útil senyoria sia consolidada ab la directa [senyoria] (sembla un tret d'argot jurídic).

viii. Ús repetitiu de pronoms demostratius: ús y exercici de aquella [jurisdicció], que aquell [senyor del lloc] y aquells [: els seus antecessors] han totstems tingut (I); no contravindrà en aquella [: la capitulació] ni en aquells [: los actes d'establiments] (consideracions finals).

ix. Esser com a auxiliar: és estat pactat (I); del tal que serà estat absent (5).

x. Ús extensiu del verb estar: en lo present any, que ja està nomenat (4) (sembla que indica no una realitat permanent sinó limitada en el temps).

xi. La construcció el/Ø + dit $+\mathrm{N}$, típica també del registre jurídic: del dit loch (preàmbul); en dit y present loch (I); que lo dit senyor (2); per dit senyor (2).

xii. $\quad$ Perífrasi d'obligació: se à de pagar (9).

xiii. Usos antiquats del relatiu: lo senyor qui ha de ser (preàmbul); y llö̈sme qui [: que] voldrà imposar per aquells o reservar per a la senyoria (I4).

xiv. Relatiu àton amb l'article: la desena part del ques culliran (9); y del que6 restarà (9).

xv. Usos preposicionals poc habituals: comensant la primera paga a Nadal (2).

xvi. Fórmules redundants: han totstems tingut y acostumat tenir (I); reservant-se com se reserva (20); dix que lloava y aprovava, segons que lloa y aprova (consideracions finals).

xvii. Fórmules de coordinació intensiva: sien tinguts y obligats a fer y tenir (5); sien tenguts y obligats a pagar $\mathrm{I} 6$ ).

xviii. Construccions estranyes: $l i$ és concedit y permès, $y$ aquell $[=\mathrm{a}$ ell $]$ y a sos antesessors (I). 
Finalment, cal destacar un notable desplegament de recursos lèxics i fraseològics, dels quals hem fet també una selecció:

i. a bé millorar y no res deteriorar (6) (fórmula que sembla que no es troba documentada).

ii. ab què [: amb la condició que] les [vitualles] que traurà, tinga facultat de fer altra fanecada de alfals ab què [: amb la condició que] pague altres deu sous (9).

iii. alfarrassar: se haja de alfarrasar per dos experts (I5) (els diccionaris històrics no han trobat documentació antiga d'aquesta verb que té el sentit de 'avaluar a ull la quantitat o vàlua d'alguna cosa', per la qual cosa aquesta és la primera documentació històrica); la huytena part del dit alfarràs (I5).

iv. algú: sens haver-li de pagar salari algú (: cap salari) (2I); en lo qual dia senyalat y no en altre algú (8) (: i no en cap altre) (en frases negatives i referit a una realitat no personal; ús insòlit).

v. $\quad \operatorname{arbitre~(6)~(forma~medieval~del~mot,~ja~present~en~Llull~[DCVB,~s.v.~arbitri]).~}$

vi. com sia tractat que (19) ('quan es doni el cas que'; locució que no es troba documentada en els diccionaris històrics).

vii. contínuos (5) (cultisme).

viii. cunya o soca de ditarbres (I7) (mot no documentat en els diccionaris històrics).

ix. emphitheòtic (2) (és la forma antiga del mot emfitèutic, aquesta forma moderna no apareix documentada fins en el Gazophylacium de Lacavalleria).

x. en tant quant (I) (no apareix en el diccionaris històrics que entren en tant que, però es troba en Hug de Cardona, II: Col.lecció diplomàtica (I407-I482) editat per Frederic Aparisi Romero, p. 690; i en El Manual de Consells de Gandia a la fi del segle XV editat per Vicent Olaso, p. I62).

xi. encontinent (24) (adverbi que apareix en la llengua des de l'època de Llull i que desapareix pràcticament a partir de final de l'edat mitjana).

xii. $\quad e o(20)$ (conjunció antiga equivalent a $o$ ).

xiii. excepto en lo present any (4) (és clarament un llatinisme).

xiv. expressos los moros (preàmbul; els editors indiquen en nota «dubtem si és una errada del copista per expulsos»).

xv. fins tant lo dia (4) (forma reforçada de fins a que no es troba documentada en els diccionaris històrics).

xvi. garrofes: ni tallar ni arrancar oliveres ni garrofes (es refereix a l'arbre, que en la línia anterior ha anomenat garroferes; no es troba documentat en els diccionaris històrics). 
xvii. gasto: a gastos y despeses (6) (fórmula intensiva d'aparença redundant que apareix documentada en un document del contracte del retaule de Santa Anna de la Seu de Manresa de 1584).

xviii. mansanes (I4) (trobem documentat mançanes [DCVB, s.v. maçana] en el Llibre primer de la Historia Cathalana en lo qual se tracta de Historia o descripció natural, ço es, de cosas naturals de Cataluña, de Pere Gil, S. J., nadiu de Reus (I55I-I622); el nostre document és estrictament contemporani d'aquesta citació).

xix. $\quad$ ningun gènero (6) (en paral.lel a ninguna manera que apareix en la Crònica de Pere el Gran $[D C V B$, s.v. ningü]; gènero té aspecte de cultisme i és la forma que apareix en els diccionaris de Pou, Torra i Lacavalleria [DECat IV, $458 a 52-b 2])$.

$\mathrm{xx}$. pendre pocessió (I) (forma sense $r$, privilegiada per Coromines i ja documentada almenys des de 1260 — cf. DECat vi, 4I2 645$)$.

xxi. pràtica (6) (forma medieval del mot, ja present en Llull [ $D C V B$, s.v. pràctica] $)$. xxii. respective (4) (llatinisme).

xxiii. seguritat (20) (la forma tradicional del mot apareix sempre escrita seguretat, seguritat sembla que reflecteix la grafia del llatí SECURITATE).

xxiv. sent Joan (2) (forma arcaica i patrimonial, per inflexió de la $a$, que es troba amb abundància en els documents medievals).

xxv. siseres (I4) (cireres, forma que no es troba documentada en els diccionaris històrics).

xxvi. spontànea (23): donarcomissióspontànea (llatinisme documentat per primera vegada en el Liber Elegantiarum Joan Esteve de I489).

xxvii. tender: lo tender que tindrà arrendada la tenda (8) ('persona que té tenda o botiga de vendre' ja es troba en Llull $[D C V B$, s.v. tender $]$ ).

xxviii. totstems (I) (notem que en Llull ja apareix la forma tostemps [DCVB, s.v.] i aquesta és la forma general en tots els textos antics; la reconstrucció etimològica que hi trobem aquí és insòlita).

xxix. villes reals (4) (sembla forma d'influència castellana).

\subsection{LA CARTA DE POBLAMENT DE BIGASTRE (I7OI)}

S'hi observen, com en el cas anterior, vacil-lacions nombroses en l'escriptura d'uns mateixos mots: doctor (preàmbul) / dotor (preàmbul); santa yglésia (preàmbul) / santa església (preàmbul); infrascrit (preàmbul) / infraescrit (preàmbul); seixanta (I) / 
sexanta (3); almazara (IO) / almàsera (IO); basalls (IO) / vasalls (II); carniceria (22) / carnizeria (22); exepció (30) / exepsions (30); successors (37) / succesors (34), etc. Noteu l'escriptura sorprenent d'elisions i contraccions en els passatges següents: confesen la una part al altra y la altra al altra (preàmbul); prometen la una part al altra y el altra al altra (consideracions finals). En alguns casos, les grafies singulars poden atribuir-se al llatinisme: monstrant (33), etc.

Pel que fa als pronoms demostratius, cal destacar l'ús sistemàtic de les formes estel esta —en esta concòrdia (37), este efecte (30) - i l'alternança en el neutre - per zo (preàmbul) / en açò (4). Apareixen també altres formes pròpies dels registres més colloquials en els possessius - la següa (27) (seva) — i en els indefinits: qualsevols altres (3), y altres qualsevols (9). Hi ha interferència castellana en algunes formes del pronom personal — cascú a qui se le establirà cascuna de dites cases (19) (pel pronom de datiu singular $l i$ ) — o del possessiu àton: sus successors (37) —en contrast amb sos succesors (34).

La preposició $a$, seguida de vocal, incorpora un suport consonàntic i pren la forma d'aparença llatinitzant ad —ad aquells (I)—, i la preposició per a s'usa extensivament: siti per a fabricar casa (3); reconèixer per a conservació de los drets (3); per a poblar en aquell (5); per a cobrar sos pechos (4I) — cal notar un cas extrem: se haja de interpelar per a davant [: davant] de dits il.lustres senyors (34). El per a s'usa també sistemàticament en la construcció de la locució conjuntiva final: y per a què es puixa continuar y anar en aument la dita nova poblasió (preàmbul); per a què les fases reconèixer (3); per a què dits il.lustres senyors (20); per a què planament la pague (38). En una ocasió trobem la preposició per amb una forma castellanitzada: se han de administrar por los justícia y jurats (I5).

En la morfologia verbal cal destacar algunes formes estranyes del present de subjuntiu, com degüen (preàmbul; 16) o incurreixquen (30). Aquesta darrera és originada per l'analogia amb les formes dels verbs incoatius, que prenen sistemàticament les terminacions amb $i$ i amb l'increment palatalitzat: cumplixca (38), concedeixca (39), etc. També consignem la forma del gerundi deixando-ho de fer (30), sols explicable com a calc del castellà, potser perquè el notari estava molt avesat a redactar textos en aquesta llengua. Seria el cas també de escribiran (33).

Destaquem també el gerundi:prenint-los (4I) i els participis concluhit (preàmbul), avengut (preàmbul), disposta (30), inserta (42), incluïda (42), contès (42) ('contingut'), llests (conclusions finals) ('llegits'), tots ells explicables a partir d'analogies o d'interferències de diversa mena.

La conjunció copulativa apareix de vegades, però de manera gens sistemàtica, en la versió arcaïtzant: la dita e present ciutat (preàmbul) / veïns y habitadors (preàmbul).

En l'àmbit de la sintaxi podem destacar els fenòmens i les construccions següents:

Caplletra 66 (Primavera, 2019), p. 121-135 
i. $\quad$ Presència molt abundant de l'article amb valor neutre: tot lo desusdit (I); ultra de lo qual (3); que tinga per lo menys (3); tot lo demés (4); lo que Déu no permeta (I7); pagant lo que serà bastimenter (22); $y$ de lo demés (23); de lo que es farà contra esta disposició (39); tot lo en ella expressat (42); ignorància de lo assi capitulat (42); lo contengut (consideracions finals).

ii. $\quad$ Us del verb ésser com a auxiliar: són estats concordat (preàmbul) (noteu la manca de concordança); és estat pactat (2).

iii. Absència del clític hi en construccions amb haver-hi: repartint el gasto que en açò [hi] podrà haver per thafulles (4); les regalies que hy à y [hi] haurà (9).

iv. Complement directe amb a: compelir al emphiteuta (30).

v. Pronom personal referit a inanimats: narrant-se en ell la dita solemnitat (42).

vi. Confusió de preposicions a causa de la semblança fonètica de la realització oral: y ab lo mateix siti (25) (en el sentit de 'en el mateix lloc').

vii. La perífrasi d'obligació alterna amb el verb deure: se'ls ha de establir solar (3) I tot allo que com a bons y fiels vasalls degüen fer a son senyor (I6).

viii. Ús d'infinitius substantivats: el haver concluhit dites cases (3); el cobrar de dits pobladors y vasalls (4I).

ix. $\quad$ Manteniment de la preposició davant conjunció: a que regoneguen dita senyoria (3I).

x. $\quad$ Futur de probabilitat: si no serà a persona plana y abonada (38).

xi. Coordinació d'adverbis en -mentambl'escapçament del primer: ni hipotecar especial ni generalment en ningun contracte (39).

xii. Ús del relatiu qui sense determinant i amb antecedent plural: llegint-los a cascú dels subjectes a qui se establirà (42); vasalls desusdits de dit lloch, qui totes les dites coses, cascuna e sengles de aquelles, lloen (consideracions finals).

El lèxic presenta força singularitats, moltes de les quals degudes a la pressió de la llengua castellana. En presentem una selecció, ordenada alfabèticament:

i. acrehedor: a qualsevols altres acrehedors (4I) (apareix documentat en el Gazophylacium de Lacavalleria de 1696).

ii. acte guarentigi (33) (terme tècnic pertanyent a la tradició jurídica valenciana del dret de propietat senyorial).

iii. albañil (preàmbul) (com a nom d'ofici d'un home que es deia Bonifacio Garcia; en canvi: Asensio Barco, fuster, Juan Lucas y Domingo Santo, tots llauradors [preàmbul]).

7. Els editors escriuen a què. 
iv. aliviar: per aliviar-los y beneficiar-los (19) (verb d'influx castellà).

v. ànuo: rèddit ànuo (I9); ànnua pensió (I9) (cultisme pres del llatí ANNUALE 'anual'; la grafia ànuo es troba documentada en la carta de poblament de Beniatjar, del I6II — volum II de les Cartes de poblament valencianes modernes, p. 136).

vi. avenament: sobre los rechs o avenaments (I3) (mot no documentat en els diccionaris històrics; ha de tenir el sentit de 'drenatge', derivat de vena, probablement amb influx del castellà).

vii. balsa: balses, saladars (9) (ha de ser un mot d'influència castellana per 'basses'; no hi ha testimonis catalans del mot).

viii. bastimenter: pagant lo que serà bastimenter (22) (en el sentit de 'proveïdor' mot documentat en Libre dels feyts d'armes de Catalunya de Roig i Jalpí, pràcticament contemporani d'aquest text).

ix. calitat: y ab calitat (3) (notem que la forma és habitual en textos valencians des d'antic: Curial i Ausiàs [DCVB, s.v. qualitat]).

$\mathrm{x}$. carzeler: porter que serveixca de carzeler (23) (manlleu del castellà; tot i que càrcer és un mot que prové del llatí i que ja es troba documentat en Llull).

xi. dean: don Geroni Fàbregues y Verge, dean (consideracions finals) (el canonge major d'un capítol catedral; forma castellana del càrrec de degà).

xii. $\quad \operatorname{demàs~(I):~} y$ als demàs pobladors (ha de ser una forma calcada del castellà).

xiii. derrama: no puixen fer ordinasions ni derrames (I2); obligats a contribuir en totes les sises y derrames que imposaran los justicia y jurats (I4) ('contribució temporal o extraordinària', pres del castellà jurídic).

xiv. dicha:pagat son deute a dicha senyoria (28) (castellanisme que manifesta una familiaritat molt gran del notari amb textos i fórmules castellans).

xv. ello: lo assi capitulat o part d'ello (42) (forma castellana que accedeix a un text escrit valencià de manera sorprenent).

xvi. enagenar: enagenar ni transportar ninguna casa (29) (manlleu del castellà que sembla que no es troba documentat en textos catalans anteriors).

xvii. encontinent: encontinent comisades (6) (ja comentat en la carta de Petrés).

xviii. enjamés: com se haditenjamés han de quedar les thafulles sens casa (29) (apareix documentat en el Diccionario Valenciano-Castellano de Carles Ros del I764; el nostre text, doncs, pot ser la primera documentació d'aquest adverbi).

xix. entons<es >: que pasaran entons<es $>$ en la dita ciutat de Oriola (4I) (deu ser una de les primeres documentacions d'aquest adverbi castellà en textos escrits en valencià).

xx. eo: terres y cases eo solars y sitis (42) (conjunció antiga equivalent a $o$ ). 
xxi. eremar: ni arrancar, tallar ni eremar arbres (7) (mot no documentat en els diccionaris històrics; ha de tenir el sentit de 'deixar de conrear o de tenir cura').

xxii. facultativa: segons la facultativa y reservasió (37) (cal entendre-ho en el sentit de 'clàusula facultativa'; cal considerar que és la primera documentació del mot).

xxiii. ganado: cascun cap de ganado major y menor (20) (forma castellana usada potser a causa de la procedència dels pastors).

xxiv. hueco (I): seixanta pams de largària y quaranta de amplària de hueco (mot castellà).

xxv. injunció: ab injunció dels justicia y jurats de aquell (36) (injunció 'acció d'imposar peremptòriament una cosa a fer' no apareix en els diccionaris històrics amb dades d'època antiga, de manera que cal considerar que aquesta és la primera documentació del mot).

xxvi. maquila: dret de maquila y almàcera (IO) (DCVB, s.v. màquila 'mesura d'oli equivalent a una lliura o a la vuitena part d'un cadap [que és una mesura d'oli, equivalent a la vuitena part d'un cànter, que alhora és una mesura de líquids, que conté poc més d'onze litres i que serveix per mesurar principalment oli i vi]' i el documenta en el Libre de les Costums Generals Scrites de la Insigne Ciutat de Tortosa).

xxvii. medi: per medi de aquells (6) (forma documentada a partir del s. XvI [DCVB, s.v. medi]).

xxviii. monda: les mondes de les azéquies (mot no documentat fins ara; els diccionaris històrics recullen mundar 'netejar' des de Llull [DCVB, s.v. mundar; DECat v,833a47-bII documenta també mondar]).

xxix. notòrio: fer notòrio als dits il.lustres senyors (3) (té aspecte de cultisme).

xxx. pecho de cases (27) (mot pres del castellà jurídic pecho 'tribut').

xxxi. perpètuo: es puga cargar censal perpètuo (39) (cal considerar que la forma és un cultisme; apareix documentada en el Gazophylacium de Lacavalleria, d'aquests mateixos anys [1696]).

xxxii. propis: pagar de sos propis (4) (en el sentit de 'béns particulars', documentat en textos del segle XIII [DCVB, s.v. propi]).

xxxiii. puesto: $y$ en los puestos hon senyalaran (40) (apareix documentat en el Gazophylacium de Lacavalleria de 1696).

xxxiv. recibo: monstrant recibo (33) (mot del lèxic administratiu castellà que ha passat a aquest document). 
xxxv. resagos: a cobrar los censos, pechos, resagos y fadigues (33) (mot no documentat; manlleu del castellà, sembla que s'ha de referir a un impost endarrerit).

xxxvi. saladars: balses, saladars (9) (sembla que té el sentit de 'salina, lloc on es recull la sal per evaporació de l'aigua que en conté'; no es troba documentat en els diccionaris històrics).

xxxvii. semilles: sigrons o altres semilles (26) (manlleu del castellà).

xxxviii. sempre y quant: y que sempre y quant pareixerà a dits il.lustres senyors (2I) (locució no documentada en els diccionaris històrics; sembla influïda per la locució castellana siempre y cuando).

xxxix. sensembargo: sens embargo de no havertitolper a provar (3I) (locució adverbial calcada del castellà sin embargo).

xl. $\quad$ sent Juan (3) (noteu: sent Joan de la carta de Petrés).

xli. solar (preàmbul) (en el sentit en què apareix aquí 'porció de terreny destinat a bastir-hi un edifici' apareix documentat en el Dictionarium seu Thesaurus Catalano-Latinus de Pere Torra [1653]).

\section{A MANERA DE CONCLUSIÓ}

L'anàlisi lingüística que acabem de fer d'aquests dos documents jurídics valencians permet ampliar, amb dades ben precises, el coneixement de la llengua del segle $\mathrm{XVII}^{8}$ a partir d'uns documents jurídics encara tan mal coneguts com són les cartes de poblament valencianes modernes. També la perspectiva de l'ús del valencià en aquests documents ens assabenta de la pervivència tossuda de la llengua formalitzada tradicional en una parcel.la del món jurídic ben acostada a les necessitats i els interessos particulars de tants valencians anònims, que continuaren, doncs, tenint una idea estructurada i concreta de la llengua que parlaven.

Resulta sorprenent que, a hores d'ara, les cartes de poblament modernes no hagin cridat mai l'atenció dels estudiosos de la llengua, essent com són, a més, una riquíssima font per a la documentació toponomàstica (aquí no hem volgut abordar aquesta dimensió, que s'allunyava massa del nostre objectiu). Es comprèn que sigui així perquè fins fa relativament poc temps no en teníem a l'abast una quantitat suficient, $\mathrm{i}$ també perquè es tracta, en definitiva, de textos molt eixuts — avorridíssims—, entrebancats de formulismes legals, que se situen als antípodes dels model literaris d'interès.

8. La síntesi que n’ofereixen Ferrando i Nicolàs (20II) és encara la millor disponible.

Caplletra 66 (Primavera, 2019), p. 121-135 
De la brevíssima «excursió» filològica realitzada entre les cartes de poblament valencianes del XVII, i més en particular entre dos petits enclavaments a les vores de Palància i del Segura, ja en podem extreure algunes conclusions, amb tota la provisionalitat que cal. El primer document estudiat, la carta de Petrés (I6I2), manifesta una llengua hereva dels usos de la cancelleria reial d'una qualitat notable (p. 1827):

XVIII. Íttem, és estat pactat etc., que los dit vasalls y nous pobladors que seran al present y per temps seran en lo esdevenidor perpètuament, no sien obligats per via directa ni indirecta pagar ningun censal, violari ni altre gènero de càrrech ni deute causat per los senyor de dit loch que són estats ni causaran per los qui vendran ni causats per la olim aljama y moros de dit loch expulsos y antecessors a d'aquells.

Les estructures gramaticals hi són sòlides, globalment considerades, i hi ha poques concessions a les formes lingüístiques espúries o d'arrel col-loquial, com passa en general en la majoria de les cartes d'aquesta època que recull el volum de procedència — sols escadusserament hi trobem, en algun dels textos, la petja escrita de pronúncies apitxades, per exemple, com ara achau [: hajau] o machor. Hi és remarcable la presència abundant de mots i locucions que no han estat recollits pels dos grans diccionaris històrics de la llengua catalana d'Alcover-Moll i Coromines, fet que revela que aquests documents jurídics valencians són una deu rica per a futures recerques en la història del lèxic català.

L'escriptura del valencià, però, al llarg del segle disset va anar deteriorant-se, per la manca de l'impuls institucional i de prestigi social. Els vells clixés del llenguatge jurídic tradicional s'anaven rovellant, potser per la distància lingüística respecte de la llengua corrent, i es feien més permeables a la influència dels usos castellans, tant del registre jurídic — cada cop més familiar- com de registres més comuns. Tot això es pot apreciar amb força claredat en la carta de poblament de Bigastre de l'any I70I. També es produeix, a mesura que avança el sis-cents, com hem explicat, una progressiva reculada de l'ús mateix del valencià en aquests tipus de documents, fins que desapareix del tot, precisament, després de la carta de Bigastre.

Al petit indret de Bigastre, com a la major part de la comarca del Baix Segura, el valencià degué extingir-se, justament, a principis del segle XviII, arran de les repoblacions de murcians promogudes pel cardenal Belluga. ${ }^{9}$ Fins al I702, el capítol catedralici d'Oriola escriu encara tota la seva documentació en valencià i castellà. En aquell moment, els notaris s'havien familiaritzat sens dubte amb els usos jurídics

9. Sobre aquesta qüestió cal veure el documentat estudi de Mercedes Abad (I994). Naturalment, són també de referència obligada els diversos treballs de Brauli Montoya sobre la substitució lingüística en les terres del sud valencià durant l'edat moderna (vegeu esp. 1986 i 1989). 
de la llengua castellana i per això impregnen els documents múltiples contaminacions lingüístiques, que no impedeixen tanmateix l'aparició ocasional d'algunes fórmules de rara bellesa i genuïnitat com la que exhorta a cultivar les dites terres segons ús y costum de bons llauradors y pràctica de la terra (27). Els pagesos experts hi pogueren, certament, fer un bon ús de la terra fèrtil que els era concedida; el bon ús lingüístic, però, hi havia de quedar irremissiblement arraconat.

\author{
Francesc Feliu \\ Universitat de Girona \\ francesc.feliu@udg.edu \\ ORCID OOOO-0003-1329-7328 \\ JoAn Ferrer \\ Universitat de Girona \\ joan.ferrer@udg.edu \\ ORCID oOoo-oooI-5625-4673
}

\title{
REFERÈNCIES BIBIOGRÀFIQUES
}

Авad Merino, Mercedes (1994) El cambio delengua en Orihuela:estudiosociolingüisticohistórico del siglo XVII, Múrcia, Universidad de Murcia.

Amillo Alegre, Francisco (20Io) «Les Cartes de Poblament: introducció», Sarrià. Revista d'Investigació i Assaig de la Marina Baixa, 5, p. 6-16.

Ferrando, Antoni \& Miquel Nicolàs (20II) Història de la llengua catalana (Nova edició revisada i ampliada), Barcelona, Editorial UOC, p. 257-26o.

Fullana, Olga (20I7) «Fe de llengua. El català dels notaris catalans als inicis de l'època contemporània», Ianua. Revista Philologica Romanica, I7, p. 49-60.

Guinot, Enric \& Manuel Ardit, ed. (2015-2017) Cartes de poblament valencianes modernes (segles XVI-XVIII), València, Universitat de València («Fonts històriques valencianes»).

Montoya, Brauli (1986) Variació i desplaçament de llengües a Elda i a Oriola durant l'Edat Moderna, Alacant, Institut d'Estudis Juan Gil-Albert.

— (1986), La interferència lingüistica al sud valencià, València, Generalitat Valenciana. 